OPEN ACCESS

Edited by:

Wenjin Guo,

Jilin University, China

Reviewed by:

Haowen Jiang,

Shanghai Institute of Materia

Medica (CAS), China

Feng Zhao,

Yantai University, China

${ }^{*}$ Correspondence:

Yuling Liu

ylliu@imm.ac.cn

Specialty section:

This article was submitted to

Inflammation,

a section of the journal

Frontiers in Immunology

Received: 23 December 2021

Accepted: 13 January 2022

Published: 18 February 2022

Citation:

Liu $Y$, Jiang $Y$, Yang $Y$, Wang $H, Y e J$, Liu D, Chen Y, Lian C, Wang R, Gao Y,

Meng Y, Gao L and Liu Y (2022) Houttuynia Essential Oil and its SelfMicroemulsion Preparation Protect Against LPS-Induced Murine Mastitis by Restoring the Blood-Milk Barrier and Inhibiting Inflammation.

Front. Immunol. 13:842189. doi: 10.3389/fimmu.2022.842189

\section{Houttuynia Essential Oil and its Self- Microemulsion Preparation Protect Against LPS-Induced Murine Mastitis by Restoring the Blood-Milk Barrier and Inhibiting Inflammation}

\author{
Yuanyuan Liu ${ }^{1,2}$, Yu Jiang ${ }^{1,2}$, Yanfang Yang ${ }^{1,2}$, Hongliang Wang ${ }^{1,2}$, Jun Ye ${ }^{1,2}$, \\ Dongdong Liu ${ }^{1,2}$, Yanmin Chen ${ }^{1,2}$, Chunfang Lian ${ }^{1,2}$, Renyun Wang ${ }^{1,2}$, Yue Gao ${ }^{1,2}$, \\ Yingying Meng ${ }^{1,2}$, Lili Gao ${ }^{1,2}$ and Yuling Liu ${ }^{1,2 *}$ \\ 1 State Key Laboratory of Bioactive Substance and Function of Natural Medicines, Institute of Materia Medica, Chinese \\ Academy of Medical Sciences \& Peking Union Medical College, Beijing, China, ${ }^{2}$ Beijing Key laboratory of Drug Delivery \\ Technology and Novel Formulation, Institute of Materia Medica, Chinese Academy of Medical Sciences \& Peking Union \\ Medical College, Beijing, China
}

Mastitis is a common inflammatory disease caused by bacterial infection to the mammary gland that impacts human and animal health and causes economic losses. Houttuynia essential oil (HEO), extracted from Houttuynia cordata Thunb, exhibits excellent antibacterial and anti-inflammatory properties. The aim of the study was to investigate the effects of HEO and a self-microemulsion preparation of HEO (SME-HEO) on inflammation and the blood-milk barrier $(\mathrm{BMB})$ in lipopolysaccharide-induced murine mastitis. HEO and SME-HEO significantly downregulated pro-inflammatory factors TNF- $\alpha$ and IL-1 $\beta$, upregulated anti-inflammatory factor IL-10, inhibited MPO expression, and alleviated histopathological injury in murine mammary gland tissues. Additionally, HEO and SME-HEO protected the integrity of the BMB by upregulating the expression of junction proteins ZO-1, claudin-1, claudin-3, and occludin. The anti-inflammatory effect of HEO against murine mastitis was mediated by blocking the MAPK signaling pathway and expression of iNOS. By inhibiting the release of inflammatory factors and protecting the integrity of the BMB, HEO may provide a novel treatment for mastitis.

Keywords: mastitis, blood-milk barrier, iNOS, ERK1/2, MAPK, houttuynia essential oil

\section{INTRODUCTION}

Mastitis, which is mainly caused by pathogenic infection, can result in impaired mammary function and bacteriological changes in milk (1). In humans, mastitis mostly occurs in lactating women, seriously affecting their quality of life, breastfeeding capability, and newborn health, and also posing a burden on the healthcare system $(2,3)$. In animals, mastitis mostly occurs in dairy cattle, with an incidence rate of up to $33 \%$. Mastitis in a dairy herd can severely impact the yield and quality of milk production, causing substantial economic losses each year and posing a human health hazard $(4,5)$. 
Currently, antibiotics such as penicillin or cephalosporin are often used to treat mastitis in clinical practice, although glucocorticoid therapy is used in severe cases $(6,7)$. Antibiotic treatment not only fails to effectively inhibit the inflammatory response, but it also promotes the generation of drug-resistant bacteria, while hormone therapy may cause systemic toxic side effects. Moreover, drugs can be secreted in milk, resulting in economic loss due to discarded milk and posing a human health threat from exposure to drug residues. Realizing "anti-hormone and anti-antibiotic therapy" in mastitis has become a clinical problem of global concern that urgently needs to be solved.

Houttuynia cordata Thunb, a heat-clearing and detoxifying traditional Chinese medicine (TCM), has been widely used to treat ailments of the respiratory and digestive tracts and infectious diseases (8-10), demonstrating potent antibacterial, antiviral, and anti-inflammatory properties $(9,11,12)$. Known as a natural antibiotic, houttuynia essential oil (HEO) is the main active constituent of $H$. cordata Thunb, of which houttuynin (Hou) has been identified as the main active component. However, because of its containing $\beta$-aldehyde-ketone structure, Hou is prone to degradation and polymerization (13), significantly reducing the efficacy and safety of HEO and hindering the clinical use of related preparations (14-16). To address these concerns, we hypothesized that a selfmicroemulsion of HEO (SME-HEO) might effectively improve the stability of $\mathrm{HEO}$ and exert a therapeutic effect against mastitis.

The blood-milk barrier (BMB) plays an important role in mammary gland function, which is adversely affected if the integrity of the BMB is compromised $(17,18)$. Studies have shown that lipopolysaccharide (LPS)-induced mastitis activates the MAPK and NF- $\mathrm{KB}$ signaling pathways (19-22), resulting in the destruction of mammary tissue structure and damage to $\mathrm{BMB}$ integrity (23). Inhibiting the release of inflammatory factors in mammary gland tissue and protecting the integrity of the BMB may play an important role in the treatment of mastitis. Therefore, the aim of this study was to investigate the effects of HEO and SME-HEO on the inflammatory response and BMB in a LPS-induced murine mastitis model.

\section{MATERIALS AND METHODS}

\section{Chemicals and Reagents}

$H$. cordata Thunb was provided by Yichang Jiahao Ecological Agriculture Development Co., Ltd. (Wuhan, China). Labrasol and Transcutol HP were obtained from Gattefosse (Saint-Priest Cedex, France). LPS was obtained from Sigma Chemical Co. (St. Louis, MO, USA). Dexamethasone sodium phosphate (DEX) was obtained from Aladdin Biotech Co. Ltd. (Shanghai, China). The multifactor detection kit was purchased from Biolegend (San Diego, CA, USA). TRNzol total RNA extraction reagent was provided by Tiagen Biotech Co. Ltd. (Beijing, China). The primary antibodies claudin-3, claudin-1, occludin, and ZO-1 were obtained from Abcam (Cambridge, UK), while P65, pP65, ERK1/2, p-ERK1/2, P38, p-P38, iNOS, COX2 and $\beta$-actin were purchased from Cell Signaling Technology (Danvers, MA, USA). The $10 \times$ electrophoretic buffer solution was purchased from Beijing Pleile Gene Technology Co., Ltd. (Beijing, China). PBS was purchased from Thermo Fisher Scientific (Waltham, MA, USA).

\section{Preparation of HEO}

HEO was prepared from $H$. cordata Thunb as previously described 24).

\section{Preparation and Characterization of SME-HEO}

HEO, Tween-80, Labrasol, and Transcutol HP were mixed together, vortexed, and then centrifuged at $12,000 \mathrm{rpm}$ for 10 min to obtain SME-HEO.

To observe the microstructure of SME-HEO, an aliquot of SME-HEO was diluted $100 \times$ with distilled water at $37^{\circ} \mathrm{C}$, and then dropped onto the surface of a 200 copper wire mesh. The excess liquid was absorbed with filter paper, the emulsion was negatively dyed with $2 \%$ phosphotungstic acid solution for 2 min, and then allowed to dry naturally. The microstructure of SME-HEO was observed via transmission electron microscopy.

To characterize the properties of the microemulsion, $100 \mu \mathrm{l}$ SME-HEO was slowly added to $10 \mathrm{ml}$ distilled water at $37^{\circ} \mathrm{C}$ with a stirring rate of $100 \mathrm{rpm}$. Complete emulsification was observed within $1 \mathrm{~min}$. The average particle size, polydispersity coefficient (PDI), and zeta potential of the microemulsion was determined. Additionally, SME-HEO particle size was investigated at dilutions of $50,100,200,400$, and $800 \times$ in distilled water to evaluate the dilution stability of the microemulsion. Finally, the stability SME-HEO and $\mathrm{HEO}$ was investigated at 4 and $25^{\circ} \mathrm{C}$ for 15 days.

\section{Animals}

Pregnant BALB/c mice (7-8 weeks old) were provided by SPF Biotech Co., Ltd. (Beijing, China). All animals were housed separately and provided free access to food and water. The animal experiments were performed in accordance with the Regulations on the Use of Experimental Animals by the Beijing Laboratory Animal Management Committee and were approved by the Laboratory Animal Welfare Ethics Committee (authorization number: 20210003YZA-3R) and Sino Animal Technology Development Co., Ltd. (Beijing, China).

\section{Animal Experimental Design}

Lactating mice (3-4 days after birth) were randomly divided into nine groups $(n=6)$ (Table 1). Except for the positive group (drug administered on day 7), mice in the other groups were administered drug treatments by internal gavage once daily for 7 consecutive days, as shown in Table 1. One hour after the final drug administration, mice in the blank group were administered normal saline in the fourth pair of mammary glands by local intraperitoneal injection, while mice the other groups were injected with $50 \mu \mathrm{l}$ LPS $(0.2 \mathrm{mg} / \mathrm{ml})$. One day after LPS injection, mice were sacrificed by cervical dislocation, and mammary gland tissues were observed and collected. 
TABLE 1 | Experimental groups and drug administration.

\begin{tabular}{llcl}
\hline Group & Lable & Dose $\mathbf{( m g} / \mathbf{k g})$ & Form of administration \\
\hline Blank & NT & $/$ & Saline (i.g.) \\
model & LPS & $/$ & Saline (i.g.) \\
positive & DEX & 10 & DEX (i.p. $)^{\mathrm{b}}$ \\
HEO & HEO-L & 100 & HEO (i.g.) \\
& HEO-M & 200 & \\
& HEO-H & 300 & \\
SME-HEO & SME-L & $100^{\mathrm{a}}$ & SME-HEO (i.g. $)^{\mathrm{b}}$ \\
& SME-M & $200^{\mathrm{a}}$ & \\
& SME-H & $300^{\mathrm{a}}$ & \\
\hline
\end{tabular}

aSME-HEO groups are described according to HEO dose.

bi.g., internal gavage.

ci.p., intraperitoneal injection.

\section{Histological Assessment}

Mammary gland tissue was immersed in $4 \%$ formaldehyde solution for approximately $24 \mathrm{~h}$, dehydrated using an ethanol gradient, embedded in paraffin, and sectioned. After dewaxing, hydration, hematoxylin staining, and eosin staining ( $\mathrm{H} \& \mathrm{E}$ staining), tissue sections were observed under a light microscope to observe the degree of neutrophil infiltration in the acini of the mammary glands and the matrix density between acini.

Five visual fields were observed from each paraffin section, and damage was scored using the following criteria: 0 , no abnormalities; 1, mild injury; 2, moderate injury; 3 , severe injury; and 4, extensive severe damage.

\section{ELISA}

Mammary gland tissue was ground with PBS in a 1:6 ratio, centrifuged twice for $30 \mathrm{~min}$ at $12,000 \mathrm{rpm}$, and the supernatant was collected. The inflammatory factors IL-23, TNF- $\alpha$, IL- $1 \alpha$, IL-1 $\beta$, IL-6, IL-17A, IFN- $\gamma$, MCP-1, IL-10, IL-12P70, IFN- $\beta$, GM-CSF, and IL-27 were detected using a 13-factor detection kit, according to the manufacturer's instructions.

\section{Quantitative Reverse Transcription Polymerase Chain Reaction (qRT-PCR)}

Total RNA was isolated from mammary gland tissue using TRNzol reagent, and amplification reactions were performed to detect levels of TNF- $\alpha$ and IL-1 $\beta$. The primer sequences are listed in Table 2.

\section{Immunohistochemistry (IHC)}

Immunohistochemical staining was used to evaluate the distribution and expression of myeloperoxidase (MPO) and tight junction proteins ZO-1, claudin-1, claudin-3, and occludin in mammary gland tissue.

Paraffin sections were treated with citric acid antigen repair buffer solution ( $\mathrm{pH} 6.0$ ), followed by bovine serum albumin (3\%) for $30 \mathrm{~min}$ at room temperature. The primary antibodies were added and sections were incubated overnight at $4^{\circ} \mathrm{C}$. After washing the sections $3 \times$ with PBS ( $5 \mathrm{~min}$ per wash), the corresponding secondary HRP-labeled antibodies were added, and the sections were incubated at room temperature for $50 \mathrm{~min}$. After washing $3 \times$ with PBS (5 min per wash), the sections were stained with DAB, followed by hematoxylin. The sections were then dehydrated and sealed for microscopic examination, and the images were collected and analyzed. Positive staining was indicated by the presence of yellow-brown color while nuclei appeared blue. The positive area ratio of each image was calculated.

\section{FITC-Albumin Evaluation}

Mammary gland tissue was immersed in FITC-albumin solution for $30 \mathrm{~min}$ without light and then placed in liquid nitrogen. The frozen tissue block was balanced in a frozen slicer for $30 \mathrm{~min}$, fixed to the base with OCT (a cryo embedding agent), and 5- $\mu \mathrm{m}$ thick frozen sections were cut. Finally, DAPI was added to the frozen sections and they were sealed. The sections were observed under a fluorescence microscope and the images were collected for data analysis.

\section{Western Blotting}

Mammary gland tissue was mixed with protein lysate and ground at $50 \mathrm{~Hz}$ for $5 \mathrm{~min}$, followed by centrifugation at $12,000 \mathrm{rpm}$ for $10 \mathrm{~min}$. Subsequently, the supernatant was collected and the protein concentration was determined using a BCA kit. The proteins in each sample (total protein $60 \mu \mathrm{g}$ ) were separated using $10 \%$ sodium dodecyl sulfate-polyacrylamide gel electrophoresis (SDS-PAGE), and then transferred to a PVDF membrane. The membrane was blocked with milk for $1 \mathrm{~h}$ and then incubated with primary antibody overnight at $4^{\circ} \mathrm{C}$. After washing with TBST, the membrane was incubated with secondary antibody for $1 \mathrm{~h}$, followed by the addition of hypersensitive chemiluminescent substrate. Finally, the target proteins were examined by X-ray exposure in a dark room.

\section{Statistical Analysis}

All data were analyzed using Graph Pad Prism version 7.0 software (La Jolla, CA, USA) and were expressed as mean \pm $\mathrm{SD}$ of six independent experiments. One-way analysis of variance (ANOVA) was used to determine significant differences between groups. Statistical significance was set at $P<0.05$ or $P<0.01$.

TABLE 2 | Primer sequences for TNF- $\alpha, \mathrm{IL}-1 \beta$ and $\beta$-actin.

\begin{tabular}{|c|c|c|c|}
\hline Item & Primer & Sequence $\left(5^{\prime}\right.$ to $\left.3^{\prime}\right)$ & Length (bp) \\
\hline$T N F-a$ & Sense & ACGGCATGGATCTCAAAGAC & 116 \\
\hline TNF-a & Anti-sense & GTGGGTGAGGAGCACGTAGT & \\
\hline$I L-1 \beta$ & Sense & TGCCACCTITGACAGTGATGA & 135 \\
\hline$\| L-1 \beta$ & Anti-sense & TGTGCTGCTGCGAGATTGA & \\
\hline$\beta$-actin & Sense & CGTTGACATCCGTAAAGACCTC & 159 \\
\hline$\beta$-actin & Anti-sense & ACAGAGTACTTGCGCTCAGGAG & \\
\hline
\end{tabular}




\section{RESULTS}

\section{Characteristics of SME-HEO}

SME-HEO was transparent and homogeneous, as shown in Figure 1A. The microstructure of SME-HEO contained spherical, uniformly sized droplets without adhesion (Figure 1B). SME-HEO diluted in water yielded a transparent solution without turbidity. SME-HEO had an average particle size of $52.7 \mathrm{~nm}$ (Figure 1C), PDI of 0.384, and zeta potential of $-27.71 \mathrm{mV}$. The particle size of SME-HEO diluted 50-800 times was stable at 50-55 nm (Figure 1D). The Hou content in HEO decreased to 26.04 and $21.46 \%$ of the original sample, while that in SME-HEO was 87.3 and $63.41 \%$ of the original sample, respectively, after 15 days at 4 and $5^{\circ} \mathrm{C}$. The self-microemulsion delivery system significantly improves the stability of HEO.

\section{HEO and SME-HEO Alleviate Injury to Murine Mammary Gland Tissues}

The appearance and pathological features of the mammary gland were evaluated after treatment with LPS, HEO, SME-HEO, and DEX. The morphology of the mammary gland is shown in Figure 2. The mammary glands in the NT group were milky white, intact, and exhibited no obvious abnormalities. Compared with the mammary glands in the NT group, those in the LPS group exhibited obvious swelling and hyperemia, suggesting that mastitis was successfully induced by LPS stimulation. Injury to the mammary gland was significantly improved in the DEX group. Redness and hyperemia in the mammary gland gradually decreased with increasing HEO and SME-HEO concentrations. The mammary glands were restored to healthy appearance in the high-dose HEO and SME-HEO groups.

The pathological features of mammary gland tissue were revealed through H\&E staining (Figure 3). Compared with mammary gland tissue in the NT group, the LPS group exhibited severely damaged structures with proliferating glandular epithelial cells. However, these inflammatory symptoms were significantly alleviated in the HEO and SMEHEO groups in a dose-dependent manner. The antiinflammatory effects exhibited in the SME-HEO groups were superior to those exhibited in the HEO groups at comparative low and medium doses.

\section{HEO and SME-HEO Downregulate Pro-Inflammatory Factors and Upregulate Anti-Inflammatory Factors}

As shown in Figure 4, nine pro-inflammatory cytokines (IL-23, TNF- $\alpha$, IL- $1 \alpha$, IL-1 $\beta$, IL-6, IL-17A, IFN- $\gamma$, MCP-1, and IL-10) were upregulated in the LPS group. However, TNF- $\alpha$ and IL-1 $\beta$ were significantly downregulated in the HEO and SME-HEO groups, and IL-10 was upregulated in the high-dose HEO and SME-HEO groups. Additionally, IL-1 $\beta$ expression was inhibited more in the SME-HEO groups than in the HEO groups at comparative doses. Meanwhile, mRNA expression of inflammatory factors TNF- $\alpha$ and IL- $1 \beta$ was consistent with the expression of the pro-inflammatory factors. That is, inhibition of TNF- $\alpha$ and IL-1 $\beta$ expression gradually increased with increasing
HEO and SME-HEO concentrations (Table 3). SME-HEO tended to induce a greater inhibitory effect than HEO, but the results did not differ significantly.

\section{HEO and SME-HEO Inhibit MPO Expression}

MPO, a marker of neutrophil function and activity, can participate in the production of oxygen free radicals, thereby causing tissue damage and exacerbating the inflammatory response $(25,26)$. MPO distribution in mammary gland tissue was observed via IHC. LPS stimulation significantly increased the expression of MPO in mammary gland tissue (Figure 5). However, MPO expression decreased gradually with increasing concentrations of HEO and SME-HEO. SME-HEO inhibited MPO expression more than HEO at comparative doses.

\section{HEO and SME-HEO Protect the Blood-Milk Barrier}

The BMB is mainly composed of endothelial cells, basement membranes, epithelial cells, and tight junction proteins. The $\mathrm{BMB}$ prevents the invasion of pathogenic microorganisms, leakage of milk components, and limits the random exchange between milk and blood components $(27,28)$.

Fluorescence staining was used to observe the distribution of FITC-albumin as a reflection of BMB integrity. The greater the infiltration of FITC-albumin, the more serious the damage to the BMB. As shown in Figure 6, the BMB in the NT group was intact without infiltration, while the cinar profile in the LPS group was blurred. Damage to BMB integrity was indicated by FITCalbumin distributed in the interacinar matrix diffusing into the acinar lumen. However, FITC-albumin infiltration gradually improved with HEO and SME-HEO treatment in a dosedependent manner. These results indicated that HEO and SME-HEO exerted protective effects against LPS-induced damage to the BMB.

\section{HEO and SME-HEO Upregulate Expression of Tight Junction Proteins ZO-1, Claudin-1, Claudin-3, and Occludin}

Connexin proteins such as ZO-1, claudin-1, claudin-3, and occludin are important components of the tightly connected structure of the BMB $(29,30)$. The mechanism by which HEO and SME-HEO protect the BMB was investigated through the distribution and expression of connexins in mammary gland tissue via IHC. The expression of ZO-1 protein was severely reduced in the LPS group (Figure 7). However, ZO-1 expression increased significantly with increasing doses of HEO and SMEHEO. The expression of claudin-1 (Figure 8), claudin-3 (Figure 9), and occludin (Figure 10) demonstrated similar trends as that of ZO-1. The occludin protein content was approximately $28 \%$ less than that of the other three connexin proteins. These results suggested that HEO and SME-HEO protected the integrity of the $\mathrm{BMB}$ by increasing protein levels of ZO-1, claudin-1, claudin-3, and occludin in mammary gland tissue. 

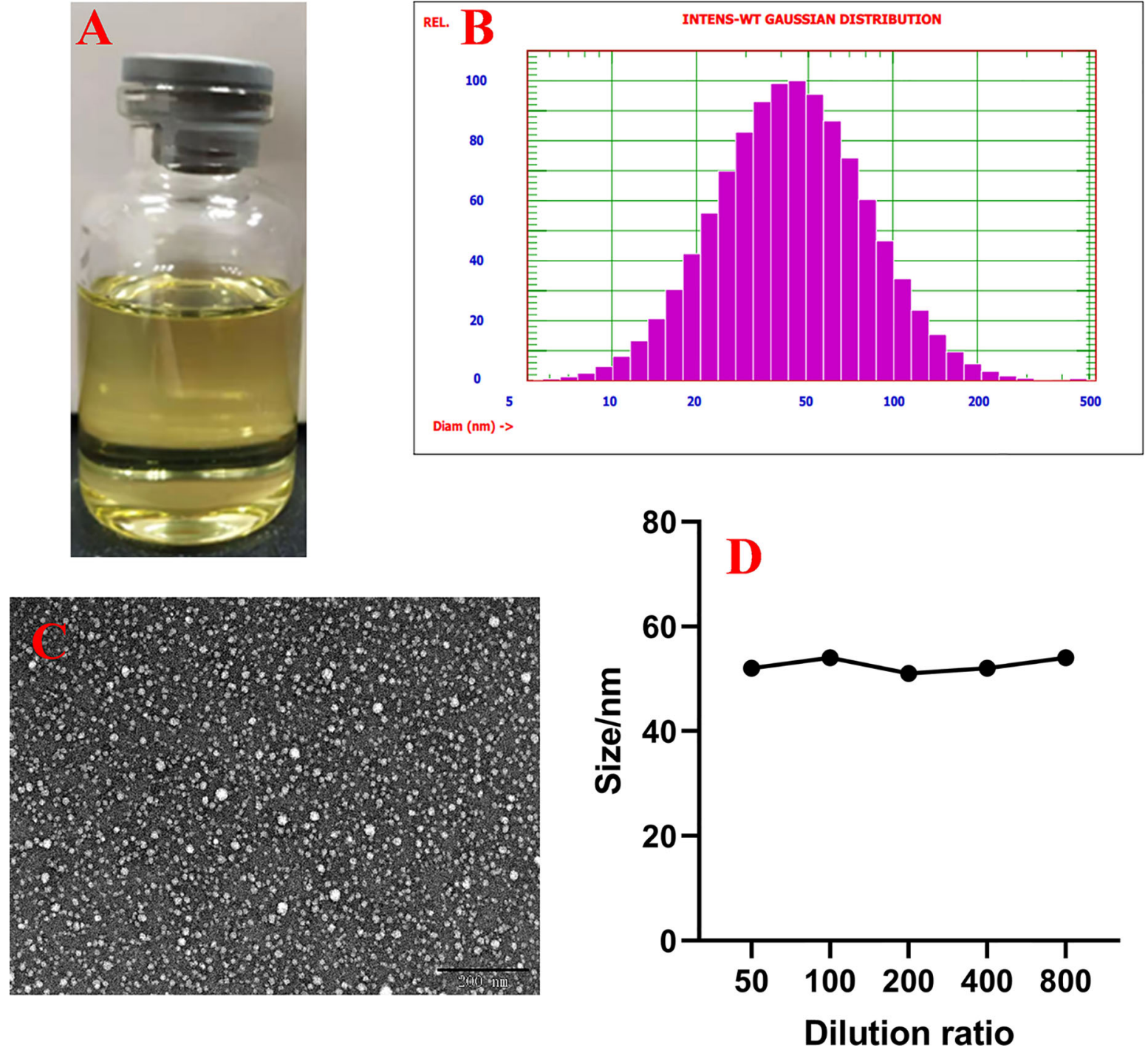

FIGURE 1 | Characteristics of SME-HEO. (A) Appearance of SME-HEO. (B) Particle size and distribution of SME-HEO. (C) Microstructure of SME-HEO. (D) Relationship between particle size and dilution ratio of SME-HEO. 


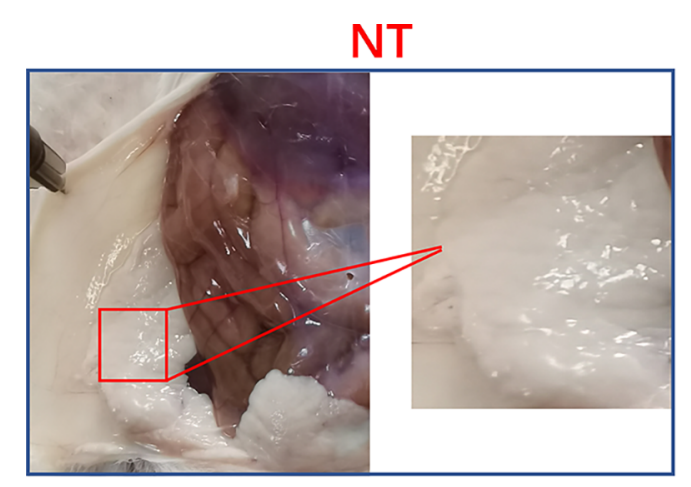

HEO-L

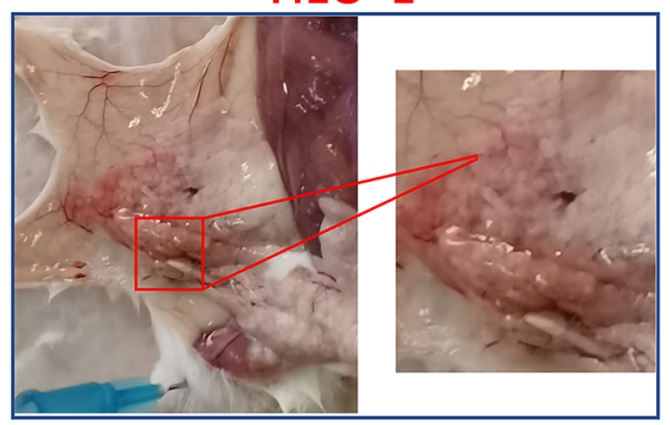

SME-L

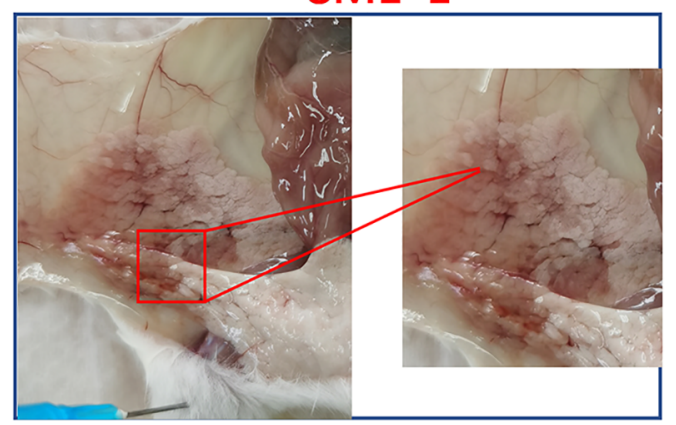

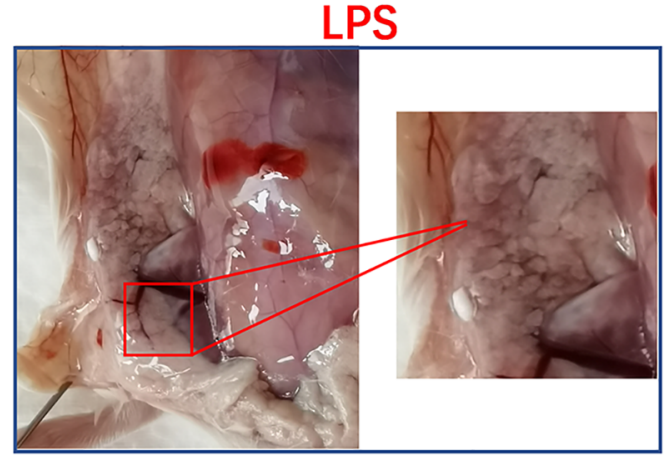

HEO-M

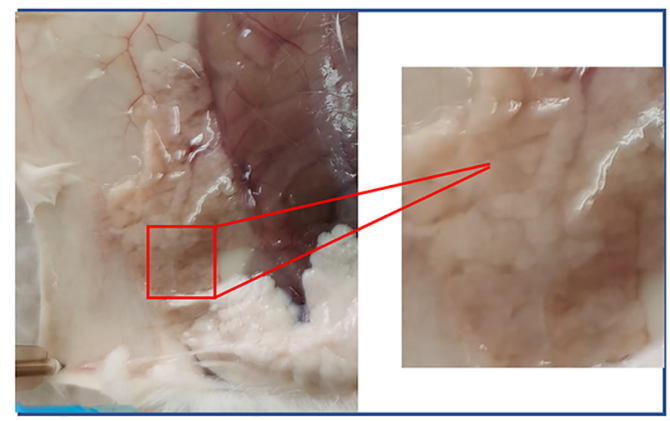

SME-M

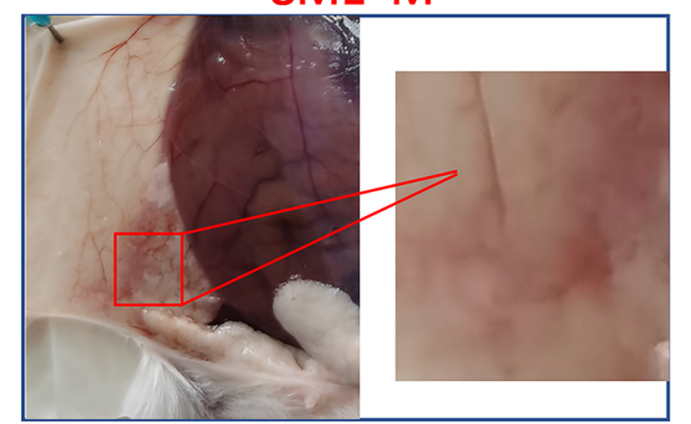

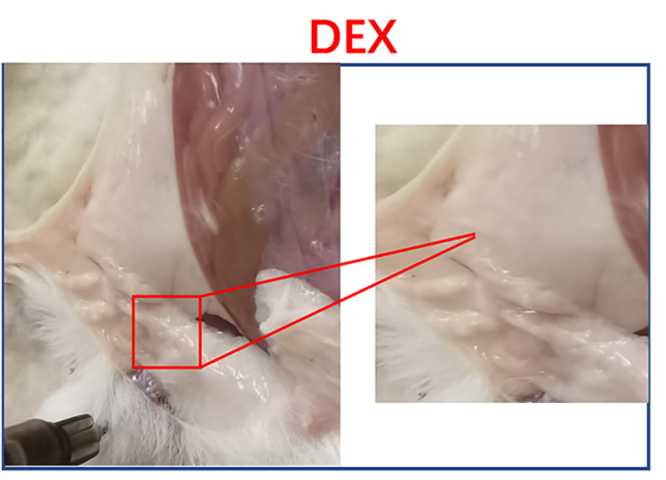

HEO-H

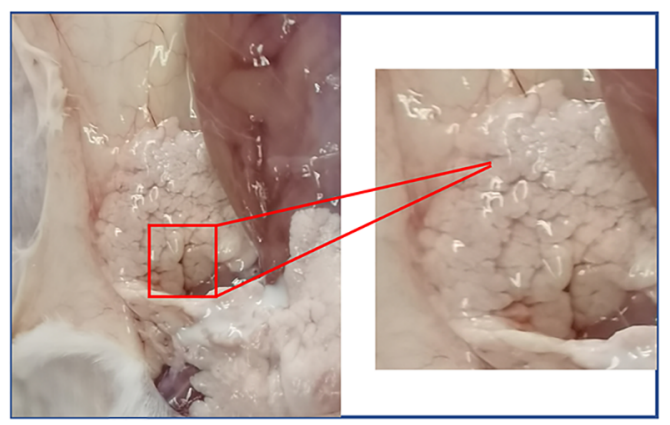

SME-H

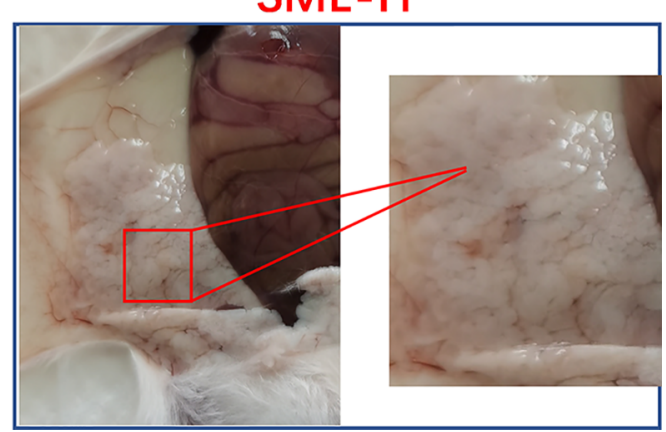

FIGURE 2 | Morphology of mammary gland tissue in LPS-induced murine mastitis. 

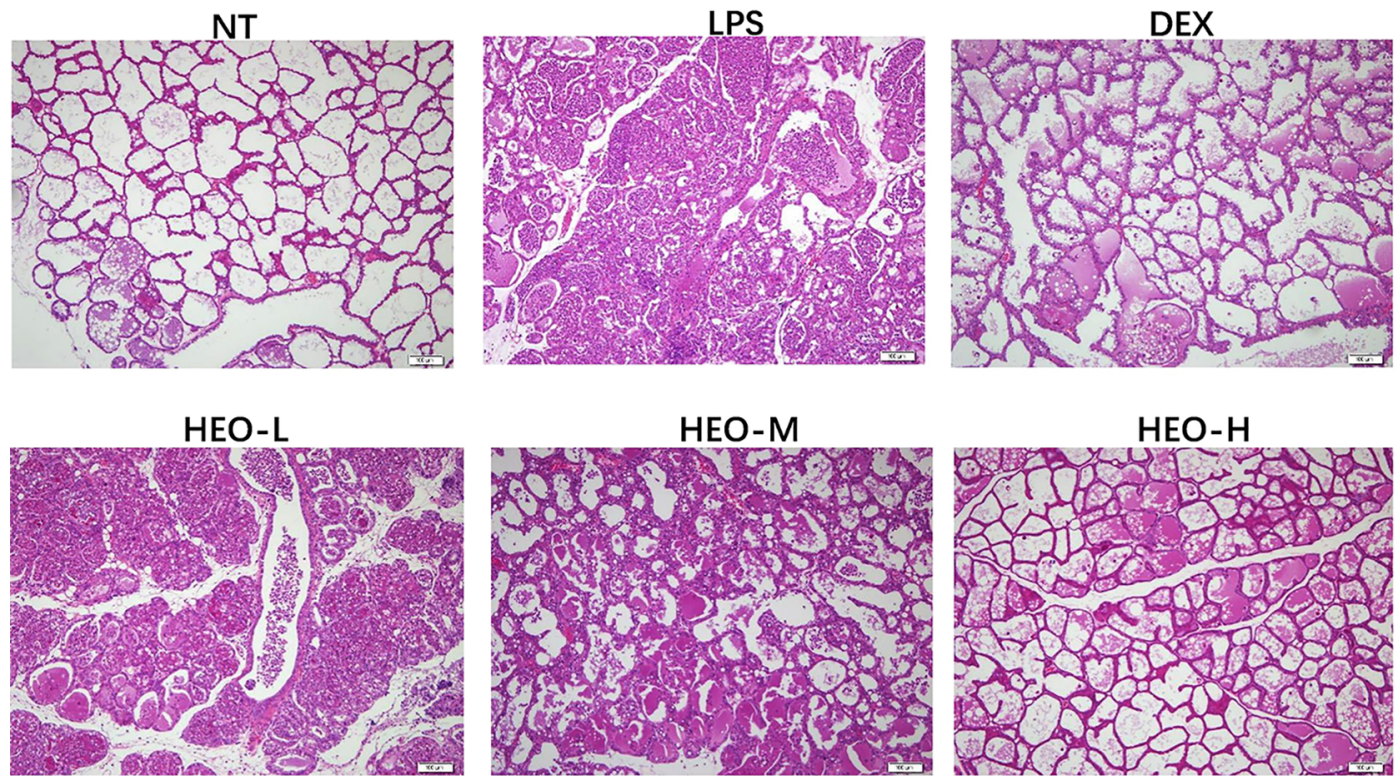

SME-L

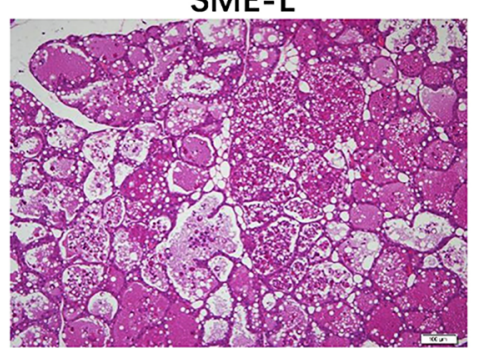

SME-M

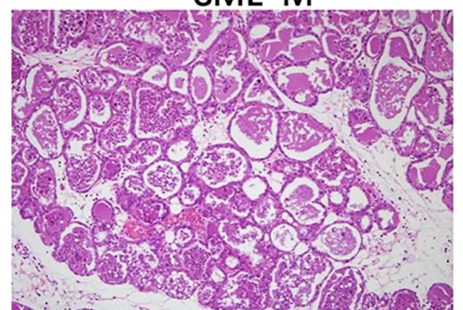

SME-H

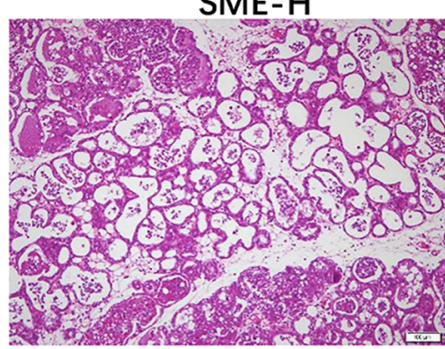

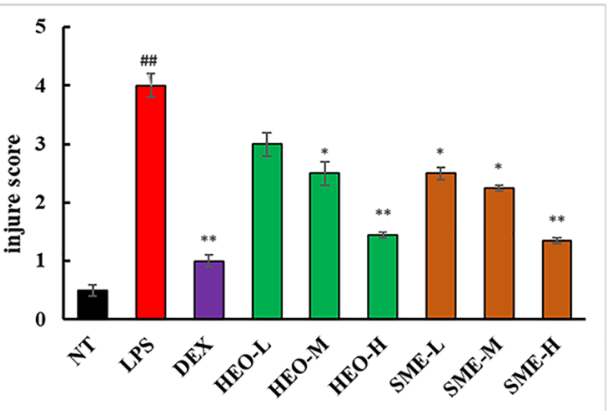

FIGURE 3 | Representative images of pathological injury to mammary gland tissue in LPS-induced murine mastitis. Mammary gland tissues from each experimental group ( $\mathrm{n}=6$ ) were obtained $24 \mathrm{~h}$ after $\mathrm{LPS}$ administration, sectioned, and stained with H\&E (magnification $\times 100)$. ( ${ }^{\# \#} P<0.01$ compared to NT group, ${ }^{*} P<0.05,{ }^{\star \star} P<0.01$ compared to model group). 


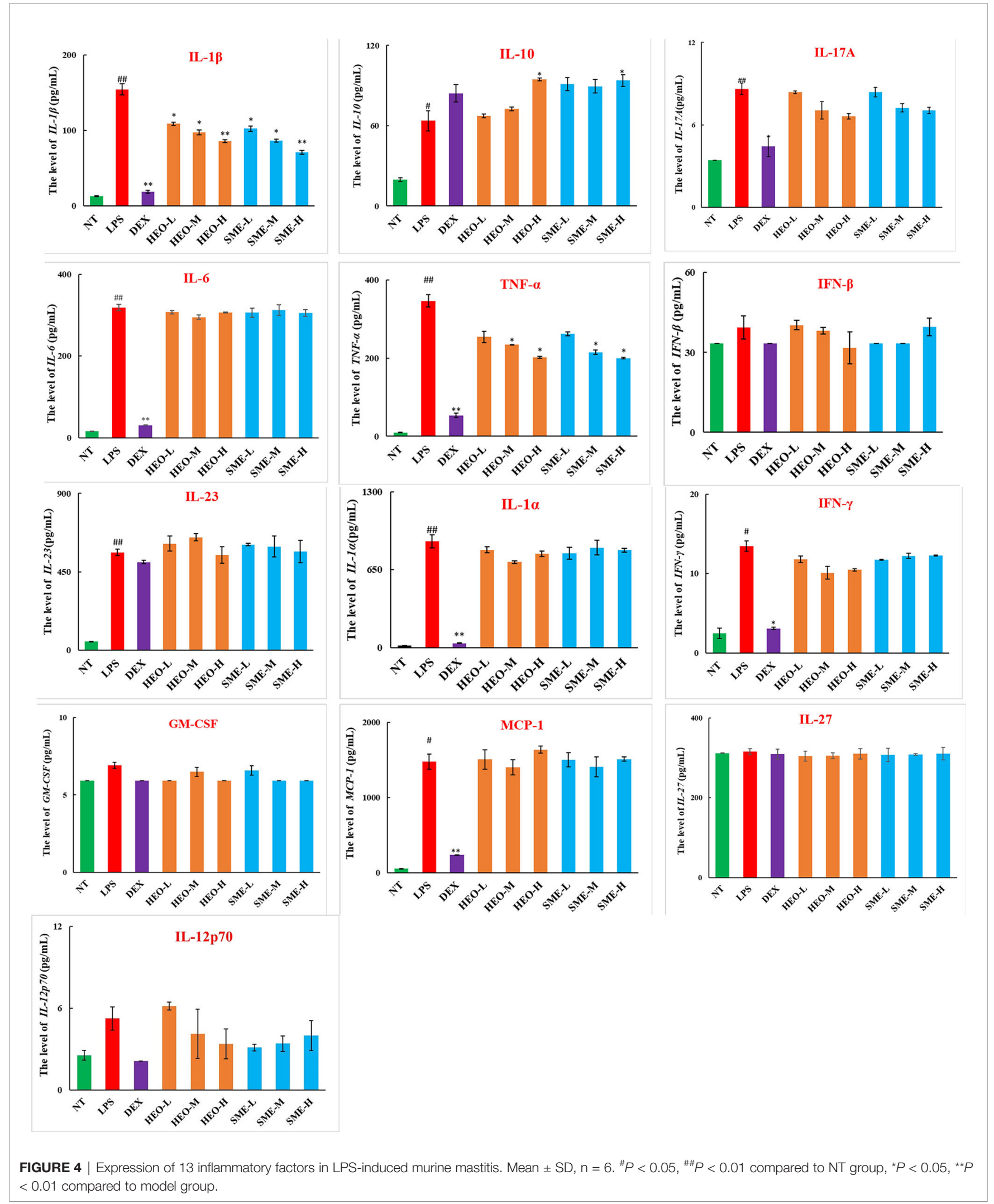


TABLE 3 | Upstream mRNA expression of TNF- $\alpha$ and IL-1 $\beta$.

\begin{tabular}{lcc}
\hline & \multicolumn{2}{c}{ Relative mRNA expression } \\
\cline { 2 - 3 } & \multicolumn{1}{c}{ TNF- $\alpha$} & IL-1 $\beta$ \\
\hline NT & $0.261 \pm 0.019$ & $0.209 \pm 0.039$ \\
LPS & $1.533 \pm 0.424^{\# \#}$ & $1.280 \pm 0.165^{\# \#}$ \\
DEX & $0.297 \pm 0.134^{\star *}$ & $0.127 \pm 0.016^{\star *}$ \\
HEO-L & $1.053 \pm 0.479$ & $0.904 \pm 0.040^{\star}$ \\
HEO-M & $0.935 \pm 0.134^{*}$ & $0.782 \pm 0.193^{\star}$ \\
HEO-H & $0.754 \pm 0.071^{*}$ & $0.457 \pm 0.002^{* *}$ \\
SME-L & $1.082 \pm 0.131$ & $0.813 \pm 0.297^{*}$ \\
SME-M & $0.565 \pm 0.285^{\star}$ & $0.638 \pm 0.297^{*}$ \\
SME-H & $0.648 \pm 0.306^{\star}$ & $0.357 \pm 0.480^{* *}$ \\
\hline
\end{tabular}

Mean $\pm S D, n=6,{ }^{\# \#} P$ compared to NT group, ${ }^{*} P<0.05,{ }^{* *} P<0.01$ compared to model group

\section{HEO Inhibits Expression of the INOS and ERK1/2/MAPK Pathways}

The expression of nitric oxide induction-type synthase (iNOS) and cyclooxygenase-2 (COX-2) is closely associated with inflammation. A large amount of NO induced by iNOS can mediate and promote the development of inflammatory diseases $(31,32)$. Moreover, COX-2 catalyzes the conversion of arachidonic acid into prostaglandins and participates in activation of the NF- $\mathrm{KB}$ pathway (33). To further explore the mechanism by which HEO alleviates mastitis, the expression of
iNOS, COX-2, and NF- $\kappa \mathrm{B}-$ and MAPK-related pathway proteins was investigated by western blotting in mammary gland tissue.

The expression of p-Akt, p-ERK1/2, p-P38, iNOS, and COX-2 proteins in mammary gland tissue increased significantly after LPS stimulation (Figure 11). The expression of iNOS and pERK1/2 proteins was significantly inhibited by HEO in a dosedependent manner, suggesting that HEO played an antiinflammatory role by inhibiting iNOS expression, ERK1/2 phosphorylation, and blocking the MAPK signaling pathway.

\section{DISCUSSION}

Mastitis commonly occurs in lactating women and has a high rate of incidence in humans and dairy cattle. At present, antibiotics are often used to treat mastitis, resulting in the misuse of antibiotics, development of drug-resistant bacteria, and other problems that may pose harm to human society. TCMs contain a variety of active substances and nutrients that can enhance immune capacity, exerting antibacterial and antiinflammatory effects with minimal side effects and without generating drug resistance. Therefore, TCMs have become the focus of research in mastitis treatment.

Although HEO exhibits potent antibacterial and antiinflammatory properties, its application in mastitis treatment has

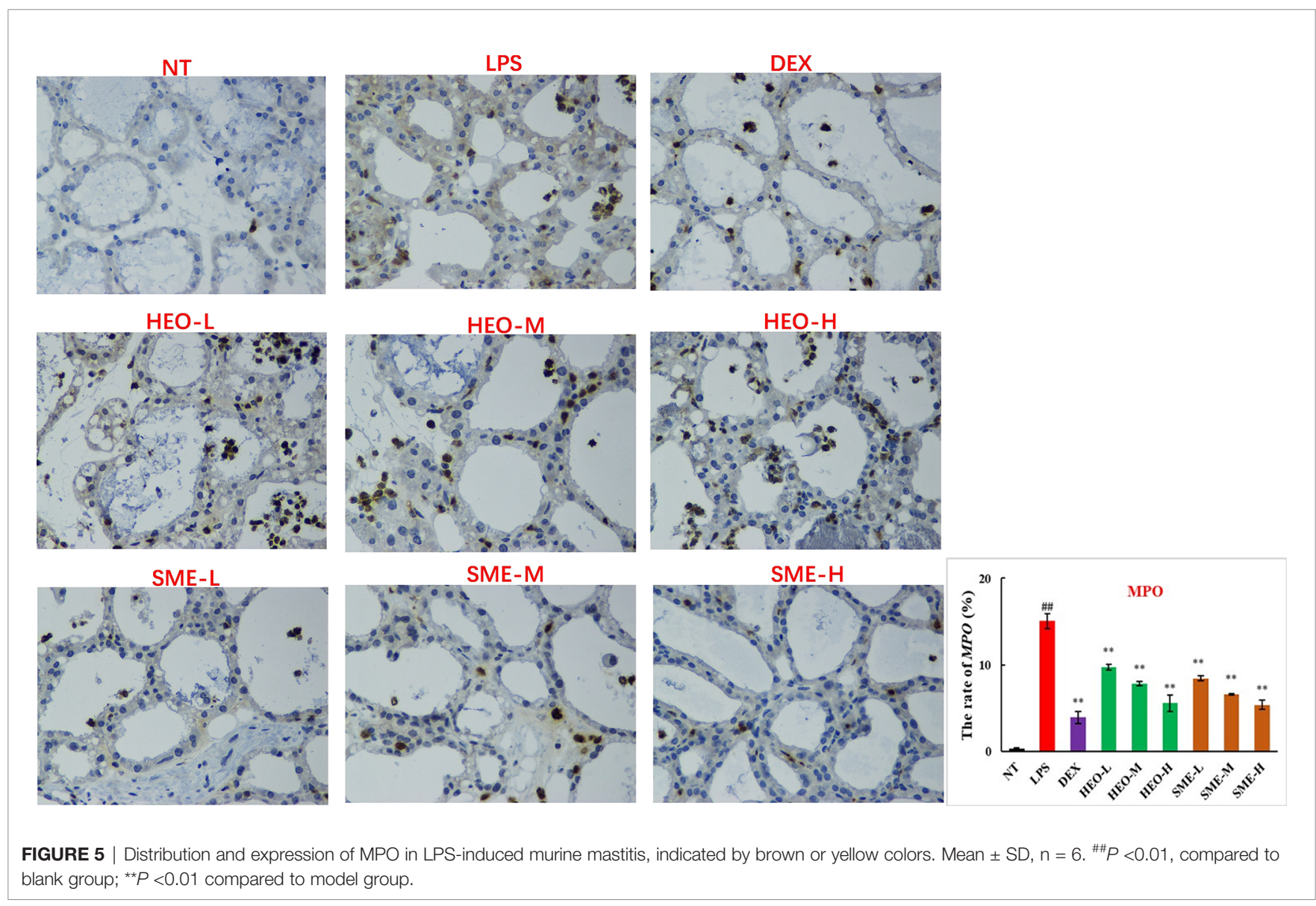




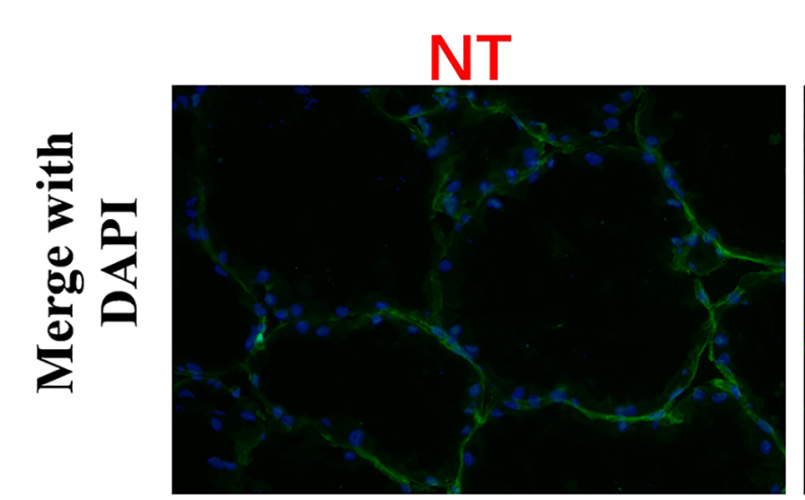

LPS

DEX

HEO-L

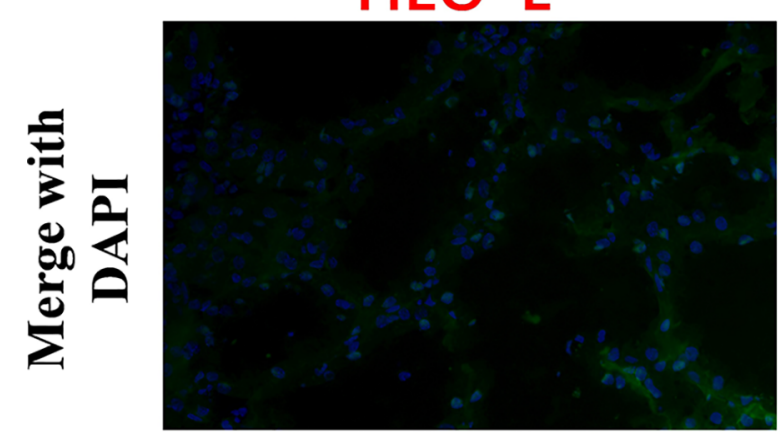

HEO-M

HEO-H

SME-L
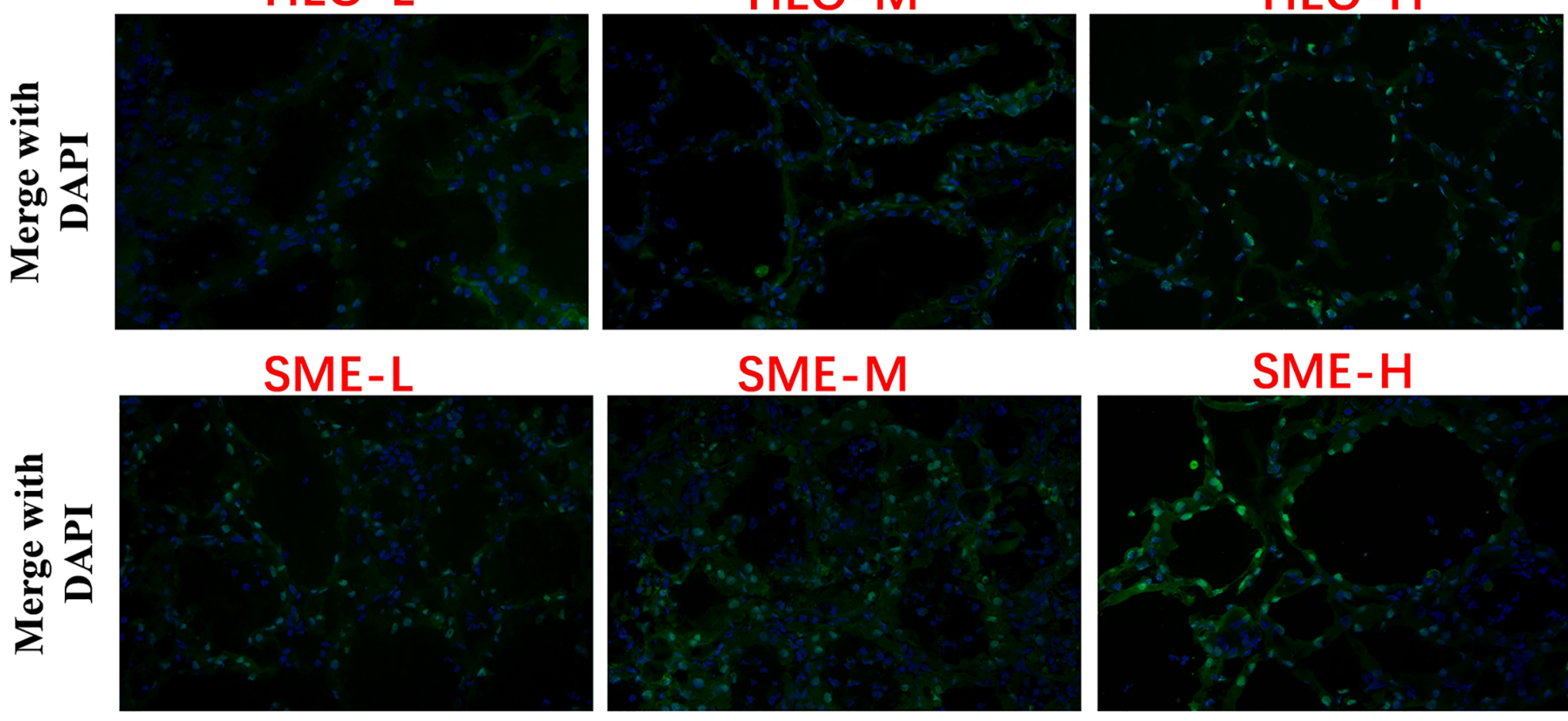

SME-M

SME-H 


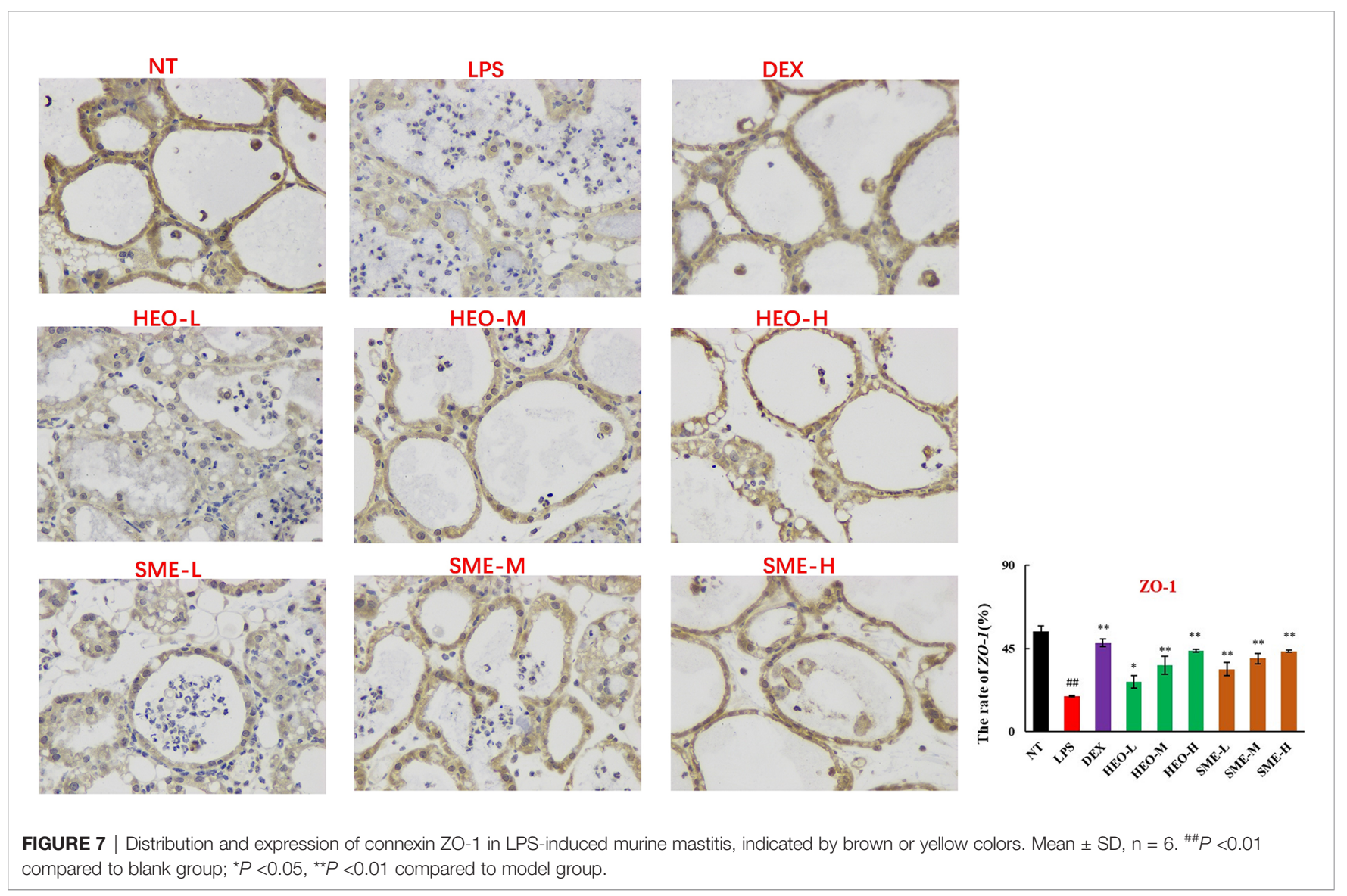

not been systematically studied. Meanwhile, the problem of HEO instability needs to be solved to improve its efficacy. On this basis, LPS was used to stimulate inflammation in murine mammary tissue, and various detection techniques were used to confirm that HEO and SME-HEO reduced the mammary inflammatory response, protected the $\mathrm{BMB}$, and alleviated the symptoms of mastitis. Further mechanistic studies revealed that HEO inhibited the expression of iNOS, phosphorylation of ERK1/2, and blocked the inflammatory MAPK signaling pathway.

Cytokines can stimulate significant upregulation of adhesion molecules in vascular endothelial cells and induce recruitment of neutrophils and macrophages to the infection site (34). In this study, 13 inflammatory factors in mammary gland tissue were detected by ELISA. The results suggested that HEO and SME-HEO treatment induced bidirectional regulation of inflammatory factors, by inhibiting the release of TNF- $\alpha$ and IL-1 $\beta$, while upregulating the expression of IL-10. The mRNA levels of TNF- $\alpha$ and IL-1 $\beta$ detected by qRT-PCR were consistent with the ELISA results. These findings confirmed that HEO and SME-HEO inhibited the expression of TNF- $\alpha$ and IL-1 $\beta$, reduced recruitment of neutrophils and macrophages to mammary lesions, and reduced damage to mammary tissue, thus exerting a protective effect against LPSinduced murine mastitis.

MPO is a member of the heme peroxidase superfamily, and its expression level and activity can reflect the state of neutrophil infiltration $(21,22)$. HEO and SME-HEO significantly reduced
MPO expression in mammary gland tissue, and the efficacy of SMEHEO was better than that of HEO at corresponding doses. These results suggest that $\mathrm{HEO}$ and its self- microemulsion preparation may inhibit neutrophil aggregation in infected mammary tissue.

BMB has important physiological functions (27-30), and maintaining its integrity is conducive to alleviating the mammary inflammatory response (35). The results of this study suggested that $\mathrm{HEO}$ and its self-microemulsion preparation protected the integrity of the $\mathrm{BMB}$ by upregulating the expression of tight junction proteins ZO-1, claudin-1, claudin-3, and occludin.

ERK1/2, a MAPK signaling pathway, is extensively involved in regulation of cell proliferation and differentiation, and plays an important role in the propagation and treatment of microorganisms $(36,37)$. For example, the levels of p-ERK are significantly increased in patients with Epstein-Barr virus (EBV)-related gastric cancer (38). Additionally, blocking the ERK1/2 pathway significantly reduces the expression of $\mathrm{EBV}$ latent membrane protein $2 \mathrm{~A}$, suggesting that the ERK1/2 pathway is also associated with infection-induced tumors. iNOS, as an intermediate of the inflammatory response, is expressed in pathological states such as inflammation, hypoxia, and tumors, and catalyzes a large amount of NO production in a short period of time. NO plays an important role in substance metabolism, information transmission, and disease prevention, and is closely related to the inflammatory response. Thus, NO content can be used as an indicator of the degree of the inflammatory response $(32,39,40)$. In the current study, HEO 

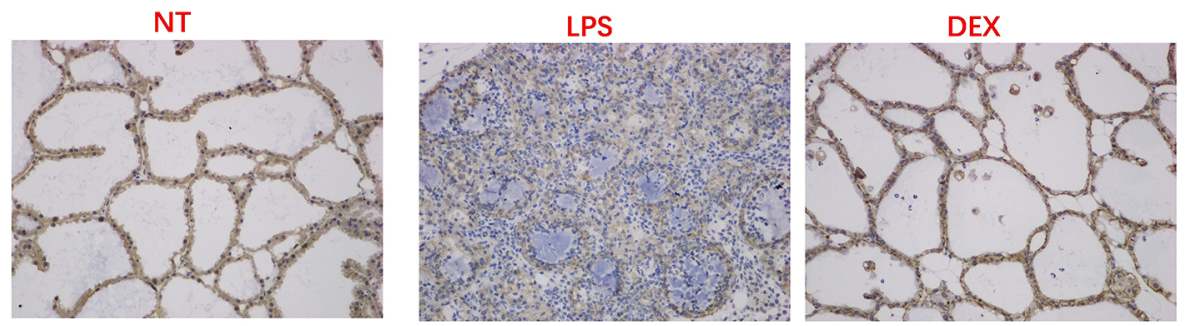

HEO-L

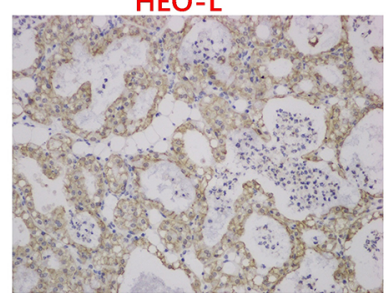

HEO-M

HEO-H
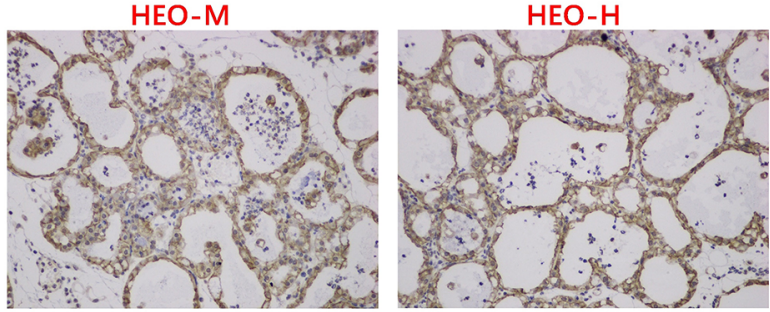

SME-L
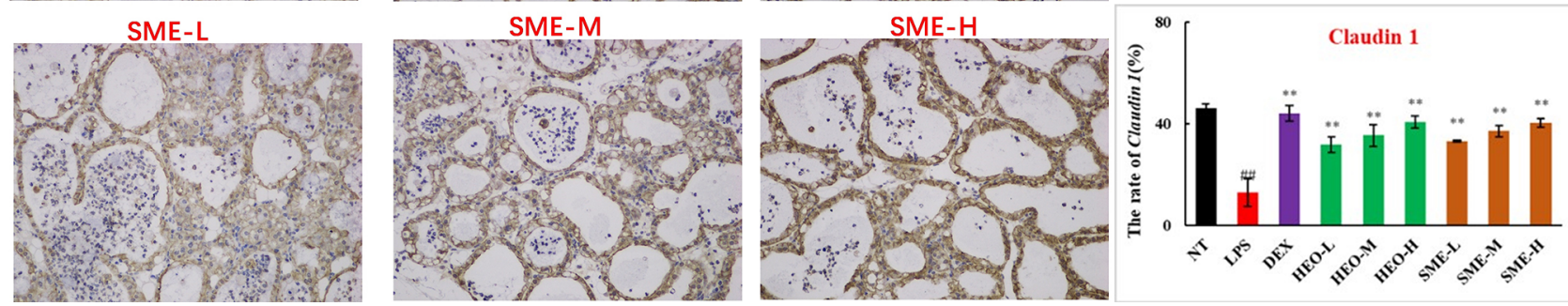

FIGURE 8 | Distribution and expression of connexin Claudin 1 in LPS-induced murine mastitis, indicated by brown or yellow colors. Mean $\pm S D, n=6 .{ }^{\# \# P}<0.01$ compared to blank group; ${ }^{* \star} P<0.01$ compared to model group.

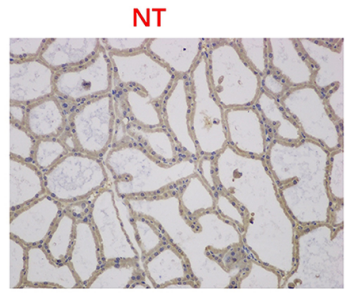

HEO-L

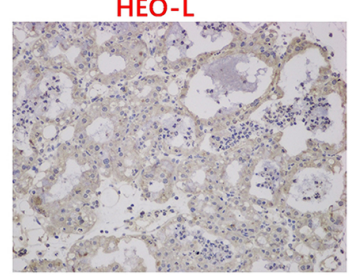

SME-L

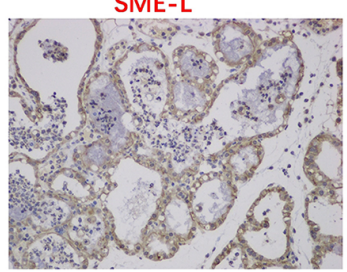

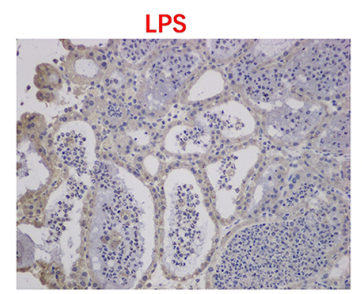

HEO-M

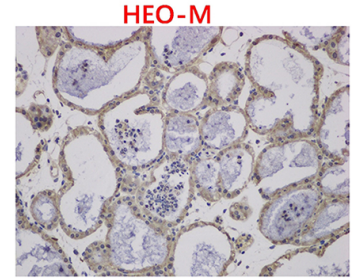

SME-M

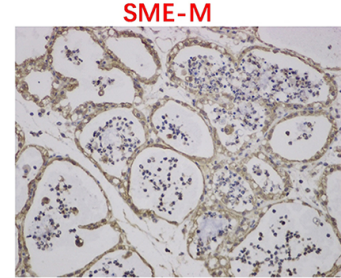

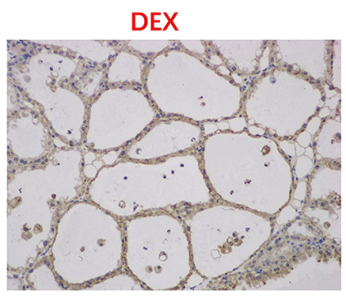

HEO-H

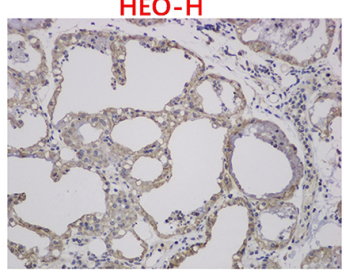

SME-H

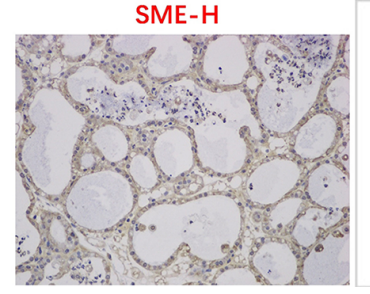

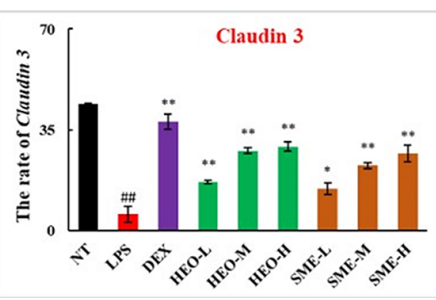

FIGURE 9 | Distribution and expression of connexin Claudin 3 in LPS-induced murine mastitis, indicated by brown or yellow colors. Mean \pm SD, $n=6 .{ }^{\# \#} P<0.01$ compared to blank group; ${ }^{*} P<0.05,{ }^{* \star} P<0.01$ compared to model group. 


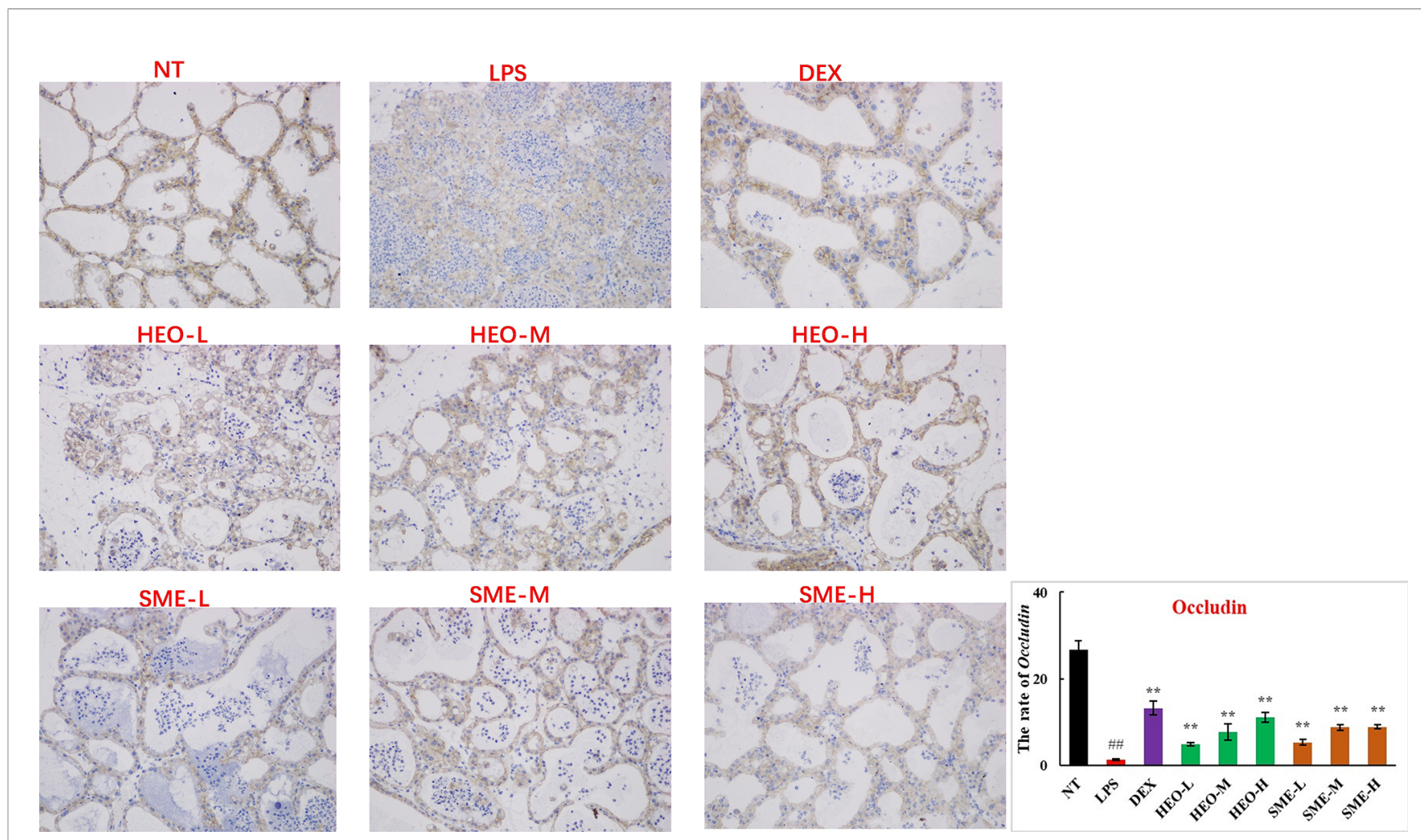

FIGURE 10 | Distribution and expression of connexin Occludin in LPS-induced murine mastitis, indicated by brown or yellow colors. Mean \pm SD, $n=6 .{ }^{\# \#} P<0.01$ compared to blank group; ${ }^{\star \star} P<0.01$ compared to model group.

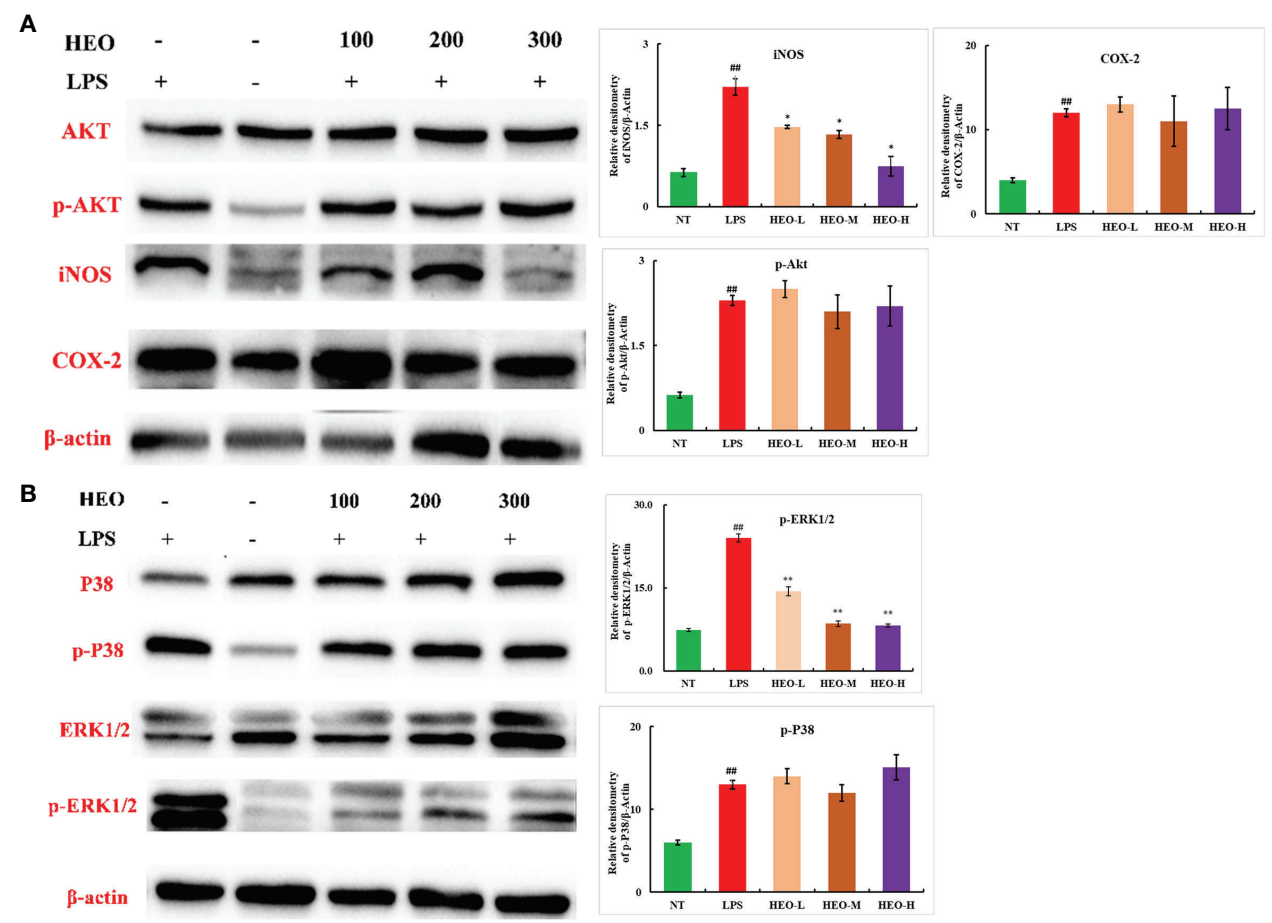

FIGURE 11 | Effects of HEO on proteins associated with inflammatory pathways. (A) HEO inhibits iNOS expression. (B) HEO hinders ERK1/2 phosphorylation. Mean $\pm \mathrm{SD}, \mathrm{n}=6$. ${ }^{\# \#} \mathrm{P}<0.01$ compared to blank group; ${ }^{*} P<0.05,{ }^{* *} P<0.01$ compared to model group. 
significantly reduced iNOS and p-ERK expression, indicating that HEO plays an anti-inflammatory role by blocking activation of the MAPK and other inflammatory signaling pathways. We speculate that HEO may have an effect on inflammatory diseases and tumors related to ERK pathway activation due to microbial infection.

In conclusion, the study findings support that HEO and SMEHEO exert therapeutic effects against LPS-induced murine mastitis, and that self-microemulsion of HEO demonstrated superior anti-inflammatory effects to bulk $\mathrm{HEO}$ to some extent. This study provides a novel strategy for the clinical treatment of mastitis without antibiotics or hormone therapy.

\section{DATA AVAILABILITY STATEMENT}

The original contributions presented in the study are included in the article/supplementary material. Further inquiries can be directed to the corresponding author.

\section{ETHICS STATEMENT}

The animal study was reviewed and approved by the Laboratory Animal Welfare Ethics Committee approved by the Sino Animal (Beijing) Technology Development Co., Ltd.

\section{REFERENCES}

1. Toquet M, Gomez-Martin A, Bataller E. Review of the Bacterial Composition of Healthy Milk, Mastitis Milk and Colostrum in Small Ruminants. Res Vet Sci (2021) 140:1-5. doi: 10.1016/j.rvsc.2021.07.022

2. Contreras GA, Rodriguez JM. Mastitis: Comparative Etiology and Epidemiology. J Mammary Gland Biol Neoplasia (2011) 16:339-35. doi: 10.1007/s10911-011-9234-0

3. Amir LH, Trupin S, Kvist LJ. Diagnosis and Treatment of Mastitis in BreastFeeding Women. J Hum Lact (2014) 30:10-3. doi : 10.1177/ 0890334413516065

4. Zhang ZY, Bao YX, Wang HL. Research Progress of Dairy Cow Mastitis. China Dairy (2021) 8:84-7. doi: 10.16172/j.cnki.114768.2021.08.016

5. Guo WJ, Liu JX, Sun JX, Gong Q, Ma H, Kan XC, et al. Butyrate Alleviates Oxidative Stress by Regulating NRF2 Nuclear Accumulation and H3K9/14 Acetvlation via GPR109A in Bovine Mammary Epithelial Cells and Mammary Glands. Free Radical Biol Med (2020) 152:728-42. doi: 10.1016/ j.freeradbiomed.2020.01.016

6. Sharun K, Dhama K, Tiwari R, Gugjoo MB, Yatoo MI, Patel SK, et al. Advances in Therapeutic and Managemental Approaches of Bovine Mastitis: A Comprehensive Review. Vet Q (2021) 41:107-36. doi: 10.1080/ 01652176.2021 .1882713

7. Godazandeh G, Shojaee L, Alizadeh-Navaei R, Hessami A. Corticosteroids in Idiopathic Granulomatous Mastitis: A Systematic Review and Meta-Analysis. Surg Today (2021) 51:1897-905. doi: 10.1007/s00595-021-02234-4

8. Mai ML, Yu LZ, Liu JS. Research on Anti - Inflammatory Effects and Clinical Application of Houttuynia Cordata Called"Antibiotics of Chinese Medicine. Pharmacol Clin Chin Mater Med (2018) 34:172-6. doi: 10.13412/ j.cnki.zyyl.2018.05.045

9. Sekita Y, Murakami K, Yumoto H, Amoh T, Fujiwara N, Ogata S, et al. Preventive Effects of Houttuynia Cordata Extract for Oral Infectious Diseases. BioMed Res Int (2016) 2016:258-66. doi: 10.1155/2016/2581876

10. Zeng HF, Zeng YF. Clinical Observation on Ultrasonic Atomization of Houttuynia Injection in Treating Chronic Pharyngitis. Jilin Med J (2016) 37:550-1.

\section{AUTHOR CONTRIBUTIONS}

YJ, HW, YC, CL, RW, DL, YG, and YuaY helped with the experiments. YF and YulL revised the contents of the article. All authors listed have made a substantial, direct, and intellectual contribution to the work and approved it for publication.

\section{FUNDING}

We are grateful for the financial support from the National Megaproject for Innovative drugs (Nos. 2018ZX09711001-002005 and 2018ZX09721003-009-001) of the Chinese government and the CAMS Innovation Fund for Medical Sciences (No. CIFMS-2019-12M-1-005).

\section{ACKNOWLEDGMENTS}

The authors would like to thank Sino Animal Science and Technology (Beijing) Development Co., Ltd. for providing a place for animal breeding, and Beijing WeHand Pharmaceutical Co., Ltd. for providing equipment support for the determination of experimental data.

11. Guo YP. Nursing Experience of Compound Houttuynia Granule in the Treatment of Acute Bronchopneumonia in Children. Nei Mongol J Tradit Chin Med (2017) 36:168. doi: 10.16040/j.cnki.cn15-1101.2017.06.156

12. Chen J, Wang W, Shi C, Fang JG. A Comparative Study of Sodium HouttuyFonate and 2-Undecanone for Their In Vitro and Invivo Anti-Inflammatory Activities and Stabilities. Int J Mol Sci (2014) 15:22978-94. doi: 10.3390/ ijms151222978

13. Zhu H, Lu X, Ling L, Li H, Ou YY, Shi XL, et al. Houttuynia Cordata Polysaccharides Ameliorate Pneumonia Severity and Intestinal in- Jury in Mice With Influenza Virus Infection. J Ethnopharmacol (2018) 218:90-9. doi: 10.1016/j.jep.2018.02.016

14. Lian CX, Gan TT, Chen H, Yuan P, Xia ZN. Determination of Binding Constant Between Sodium Houttuyfonate and Human Serum Albumin by Capillary Electrophoresis. J Chongqing Univ (2004) 27:59-62. doi: 1000-582X (2004)02-0059-04

15. Liang Y, Lu YL. Analysis of 5 Cases of Serious Adverse Drug Reactions. Adverse Drug React J (2003) 10:25-6.

16. Xu R, Jiang LM, He JM, Liu YL. The Condensation Mechanism of Sodium New Houttuyfonate and Determination of the Chemical Structure of Condensation Products. Acta Pharm Sin (2009) 44:61-5. doi: 10.16438/ j.0513-4870.2009.06.019

17. Jiang LM, Xu R, Liu YL. Degradation Kinetics of Sodium Neohouttuynium Aqueous Solution. Chin J Pharm (2008) 08:606-9. doi: 1001-8255(2008)080606-04

18. Wall SK, Gross JJ, Kessler EC, Villez K, Bruckmaier RM. Blood-Derived Proteins in Milk at Start of Lactation: Indicators of Active or Passive Transfer. J Dairy Sci (2015) 98:7748-56. doi: 10.3168/jds.2015-9440

19. Wang J, Wei Z, Zhang X, Wang Y, Yang Z, Fu Y. Propionate Protects Against Lipopolysaccharide-Induced Mastitis in Mice by Restoring Blood-Milk Barrier Disruption and Suppressing Inflammatory Response. Front Immunol (2017) 8:1108. doi: 10.3389/fimmu.2017.01108

20. Heimes A, Brodhagen J, Weikard R, Seyfert HM, Becker D, Meyerholz MM, et al. Hepatic Transcriptome Analysis Identifies Divergent Pathogen-Specific TargetingStrategies to Modulate the Innate Immune System in Response to Intramammary Infection. Front Immunol (2020) 11:715. doi: 10.3389/fimmu.2020.00715 
21. Johnzon CF, Dahiberg J, Gustafson AM, Waern I, Moazzamit AA, Ostensson $\mathrm{K}$, et al. The Effect of Lipopolysaccharide-Induced Experimental Bovine Mastitis on Clinical Parameters, Inflammatory Markers, and the Metabolome: A Kinetic Approach. Front Immunol (2018) 9:1487. doi: 10.3389/ fimmu.2018.01487

22. Guo WJ, Li W, Su YC, Liu S, Kan XC, Ran X, et al. GPR 109A Alleviate Mastitis and Enhances the Blood Milk Arrier by Activating AMPK/Nrf2 and Autophagy. Int J Biol Sci (2021) 17:4271-84. doi: 10.7150/ijbs.62380

23. Wall SK, Hernandez-Castellano LE, Ahmadpour A, Bruckmaier RM, Wellnitz O. Differential Glucocorticoid-Induced Closure of the BloodMilk Barrier During Lipopolysaccharide- and Lipoteichoic Acid-Induced Mastitis in Dairy Cows. J Dairy Sci (2016) 99:7544-53. doi: 10.3168/ jds.2016-11093

24. Liu YY, Yang YF, Wang BY, Wang RY, Pang JM, Jiang Y. Development and Verification of a Precolumn Derivatization LC-MS/MS Method for the Pharmacokinetic Study of Houttuynine of Houttuynia Essential Oil. Molecules (2021) 26:2327. doi: 10.3390/molecules26082327

25. Liu R, Xiao N, Tian KL, Diao YF, Wang ZW. Role of Delayed Neutrophil Apoptosis in the Pathogenesis of Lipopolysaccharide-Induced Acute Lung Injury in Rats. Natl Med J China (2001) 10:44-8.

26. Chniguir A, Zioud F, Marzaioli V, El-Benna J, Bachoual R. Syzygium Aromaticum Aqueous Extract Inhibits Human Neutrophils Myeloperoxidase and Protects Mice From LPS-Induced Lung Inflammation. Pharm Biol (2019) 57:56-64. doi: 10.1080/13880209.2018.1557697

27. Guo WJ, Liu BR, Hu GQ, Kan XC, Li YW, Gong Q, et al. Vanillin Protects the Blood-Milk Barrier and Inhibits the Inflammatory Response in LPS-Induced Mastitis in Mice. Toxicol Appl Pharmacol (2019) 365:9-18. doi: 10.1016/ j.taap.2018.12.022

28. Wang JJ, Wei ZK, Zhang X, Wang YN, Fu YH, Yang ZT. Butyrate Protects Against Disruption of the Blood-Milk Barrier and Moderates Inflammatory Responses in a Model of Mastitis Induced by Lipopolysaccharide. $\mathrm{Br} \mathrm{J}$ Pharmacol (2017) 174:3811-22. doi: 10.1111/bph.13976

29. Visser J, Rozing J, Sapone A, Lammers K, Fasano A. Tight Junctions, Intestinal Permeability, and Autoimmunity: Celiac Disease and Type 1 Diabetes Paradigms. Ann N Y Acad Sci (2009) 1165:195-205. doi: 10.1111/j.17496632.2009.04037.x

30. Wong V. Phosphorylation of Occludin Correlate With Occludin Localization and Function at the Tight Junction. Am J Physiol (1997) 273:C1859-67. doi: 10.1152/ajpcell.1997.273.6.C1859

31. Martin MC, Martinez A, Mendoza JL, Taxonera C, Diaz-Rubio M, FernandezArquero M, et al. Influence of the Inducible Nitric Oxide Synthase Gene (NOS2A) on Inflammatory Bowel Disease Susceptibility. Immunogenetics (2007) 59:833-7. doi: 10.1007/s00251-007-0255-1

32. Janakiram NB, Rao CV. iNOS Selective Inhibitors for Cancer Prevention: Promise and Progress. Future Med Chem (2012) 4:2193-204. doi: 10.4155/fmc.12.168
33. Gilroy DW, Colville-Nash PR, Willis D, Chivers J, Paul-clark MJ, Willoughby DA. Inducible Cyclo Oxygenase may Have Anti-Inflammatory Properties. Nat Med (1999) 6:698-701. doi: 10.1038/9550

34. Hwang PA, Chien SY, Chan YL, Lu MK, Wu CH, Kong ZL, et al. Inhibition of Lipopolysaccharide (LPS)-Induced Inflammatory Responses by Sargassum Hemiphyllum Sulfated Polysaccharide Extract in RAW 264.7 Macrophage Cells. J Agric Food Chem (2011) 59:2062-8. doi: 10.1021/jf1043647

35. Guo WJ, Liu BR, Yin YH, Kan XC, Gong Q, Li YW, et al. Licochalcone a Protects the Blood-Milk Barrier Integrity and Relieves the Inflammatory Response in LPS-Induced Mastitis. Front Immunol (2019) 10:287. doi: 10.3389/fimmu.2019.00287

36. Kohno M, Pouyssegur J. Targeting the ERK Signal Pathway in Cancer Therapy. Ann Med (2006) 38:200-11. doi: 10.1080/07853890600551037

37. Peng YH. ERK Signaling: Host Mechanisms Dependent on Virus Infection and Potential Antiviral Targets. Chin J Viral Dis (2012) 2:4-8. doi: 10.16505/ j.2095-0136.2012.06.001

38. Qi YF. Down-Regulation of COX-2 by EBV Through TRAF2 and ERK Signaling Pathways in EBV-Associated Gastric Cancer Cells. Qingdao: Qingdao University (2020).

39. Cha SM, Cha JD, Jang EJ, Kim GU, Lee KY. Sophoraflavanone G Prevents Streptococcus Mutans Surface Antigen I/II-Induced Production of NO and PGE2 by Inhibiting MAPK-Mediated Pathways in RAW264.7 Macrophages. Arch Oral Biol (2016) 68:97-104. doi: 10.1016/j.archoralbio.2016.04.001

40. Kanno S, Shouji A, Tomizawa A, Hiura T, Osanai Y, Ujibe M, et al. Inhibitory Effect of Naringin on Lipopolysaccharide (LPS)-Induced Endotoxin Shock in Mice and Nitric Oxide Production in RAW264.7 Macrophages. Life Sci (2006) 78:673-81. doi: 10.1016/j.lfs.2005.04.051

Conflict of Interest: The authors declare that the research was conducted in the absence of any commercial or financial relationships that could be construed as a potential conflict of interest.

Publisher's Note: All claims expressed in this article are solely those of the authors and do not necessarily represent those of their affiliated organizations, or those of the publisher, the editors and the reviewers. Any product that may be evaluated in this article, or claim that may be made by its manufacturer, is not guaranteed or endorsed by the publisher.

Copyright (C) 2022 Liu, Jiang, Yang, Wang, Ye, Liu, Chen, Lian, Wang, Gao, Meng, Gao and Liu. This is an open-access article distributed under the terms of the Creative Commons Attribution License (CC BY). The use, distribution or reproduction in other forums is permitted, provided the original author(s) and the copyright owner(s) are credited and that the original publication in this journal is cited, in accordance with accepted academic practice. No use, distribution or reproduction is permitted which does not comply with these terms. 